\title{
Attention-deficit hyperactivity disorder in adults: validity unknown ${ }^{1}$
}

\author{
Morris Zwi \& Ann York
}

\begin{abstract}
Attention-deficit hyperactivity disorder (ADHD) is a commonly diagnosed childhood psychiatric disorder. Debate over its diagnostic validity, aetiology, presentation and treatment has extended from the clinical to the public domain. As children with ADHD diagnoses reach adulthood there is

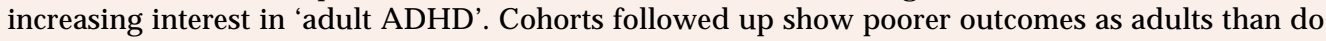
controls. Self-referred adults, sometimes relatives of children with ADHD, are also of interest regarding adult ADHD. Innovative work is being done examining issues of aetiology, treatment, outcomes and comorbidity in these groups, but heterogeneity among those diagnosed with ADHD and changes in classification systems and diagnostic criteria over time complicate comparison of research findings. The diagnostic validity of adult ADHD remains uncertain and needs further study.
\end{abstract}

This article is the first in a news series entitled 'life-span psychiatry', which considers the developmental psychiatry of adulthood. Subsequent articles will discuss autistic-spectrum disorders, early developmental aspects of psychopathy and psychosis and training implications.

The diagnosis of attention-deficit hyperactivity disorder (ADHD) in children has attracted much argument and controversy. Polarised opinion ranges from those who believe it is a myth and does not exist to those who argue that there is both genetic and physiological evidence of its existence (Jadad, 1999).

Similar controversy is expected for the concept of adult ADHD, as the debate will certainly grow with the increasing research, public awareness and interest surrounding the disorder.

Public fascination with ADHD has grown since the late 1980s (Weiss et al, 2002) and the internet has further increased the availability of information, often unevaluated, and led to the establishment of many ADHD support groups (e.g. the Attention Deficit Disorder Information and Support Service in the UK; website http://www.addiss.co.uk/). In March 2003 an internet search using the term ADHD and the Google search engine revealed 80 pages of links.

1. For an invited commentary on this article see Asherson (2004, this issue: pp. 257-259). For a related editorial see Green (2004, this issue: pp. 241-242).
As children with a diagnosis of ADHD grow into adulthood, adult mental health services will increasingly be faced with responsibility for their care. This demand has already been identified in the UK and has led to the establishment of a specialised service (Toone et al, 1997; Young \& Toone, 2000).

We both work with children and adolescents diagnosed with ADHD and form impressions of them and their families. This in turn influences our ideas and beliefs. We have read and appraised a wide range of work, but in preparing this article we did not use a systematic, transparent methodology such as that outlined in the Cochrane Reviewer's Handbook (Clarke \& Oxman, 2003). We offer a narrative rather than a systematic review, biased through our interest in the issues. Our aims are to highlight these and to encourage debate.

\section{Evolution of the concept}

The concept of ADHD has developed over time, and diagnostic criteria continue to evolve. In 1902, Still described children with hyperactivity and poor attention skills as having a 'defect of moral control' (Still, 1902). As early as 1937, Bradley wrote about the use of amphetamines in children to reduce hyperactivity (Bradley, 1937), and by the 1940s and 1950s the condition was attributed to 'minimal brain

Morris Zwi is a consultant child and adolescent psychiatrist with South West London \& St George's Mental Health NHS Trust (Child and Family Consultation Centre, Richmond Royal, Kew Foot Road, Richmond, Surrey TW9 2TE, UK. E-mail: morris.zwi@swlstg-tr.nhs.uk). In addition to attention-deficit hyperactivity disorder, his special interests include evidencebased practice and the politics of health care. Ann York is a consultant and honorary senior lecturer in child and adolescent psychiatry at the Child and Family Consultation Centre, Richmond Royal, and at St George's Hospital Medical School, London. Her special interests include neurodevelopmental disorders, depression, training and service design. 
damage'. Later, it was renamed 'minimal brain dysfunction' because of the absence of evidence for actual brain lesions, and then as 'hyperkinetic impulse disorder' (Barkley, 1990).

In the 1960s, 'minimal brain dysfunction' was replaced by a variety of more differential concepts such as dyslexia, learning disability and hyperactivity, and by 1970 'hyperkinetic child syndrome' was used to describe impulsive children with short attention spans, distractibility and aggression (Barkley, 1990). DSM-II (American Psychiatric Association, 1968) described criteria for 'hyperkinetic reaction of childhood', and by 1980 the DSM-III 'attention-deficit disorder' was defined with two subtypes, with and without hyperactivity (American Psychiatric Association, 1980).

DSM-III was the first classification system to raise the possibility that symptoms might continue into adulthood as 'attention-deficit disorder (hyperactivity), residual state'. It also defined two subtypes: one focused on clinically significant problems with attention and the other on both inattention and hyperactivity-impulsivity.

The term 'attention-deficit hyperactivity disorder' first appeared in DSM-III-R (American Psychiatric Association, 1987) and its use has continued in the trend towards extension of the disorder to adults, for whom 'impairment in the workplace' is specifically mentioned. Despite this trend away from childoriented symptom criteria, field trials for the current DSM-IV diagnostic criteria did not involve adults (Weiss et al, 2002). DSM-IV defines three subtypes: predominantly inattentive, predominantly hyperactive-impulsive and combined (American Psychiatric Association, 1994).

In the UK and the rest of Europe, researchers have used additional diagnostic frameworks. The ICD-10 (World Health Organization, 1992) classification 'hyperkinetic disorder' is similar to DSM-IV's ADHD (combined type), but its criteria are even more restricted: 'a persistent and severe impairment of psychological development resulting from a high level of inattentive, restless and impulsive behaviour'. By definition, the onset of hyperkinetic disorder is before the age of 7 years, but it is frequently recognised in children less than 2 years old (Taylor et al, 1998). All three problems (attention deficit, hyperactivity and impulsiveness) must be present, more stringent criteria exist for the 'pervasiveness' of the condition across situations, and symptoms of other disorders are absent, apart from conduct disorder, which may be present as part of the subtype 'hyperkinetic conduct disorder'.

In a series of papers on a community-based child population from 1983 to 2000, Swedish researchers have described a disorder called 'deficits in attention, motor control and perception' (Rasmussen \& Gillberg, 2000). This is similar to ADHD combined with developmental coordination disorder.

\section{Diagnostic validity}

The core symptoms of ADHD - inattention, hyperactivity and impulsivity - are normal behavioural traits present in children without the disorder. The extent to which each causes disability varies and should be seen within the context of a child's developmental level. An active 3-year-old, impulsive and frequently interrupting of others, for example, differs from a disruptive, unfocused 8-year-old unable to cope educationally. Yet both are displaying core symptoms of ADHD (Zwi et al, 2000).

Clinical judgements are therefore made as to whether these traits are present to a greater extent than 'normal'. Judgements are also made as to whether they impair the function of the individual. Not surprisingly, therefore, children with ADHD are heterogeneous in respect of their problem presentation and clinical needs (Klassen et al, 1999). The absence of a validated diagnostic test to confirm a clinical diagnosis means that the diagnosis is related to the perceived degree of impairment due to the core symptoms and their pervasiveness in a range of situations. Field trials are therefore undertaken to validate diagnostic criteria; for DSMIV ADHD these include the trials reported by Frick et al (1994), Lahey et al (1994) and Applegate et al (1997).

The high interrater reliability between expert assessors in such trials increases the internal validity of the concept but may have little effect on external validity. For example, the subjective nature of judgements on the presence or absence of diagnostic criteria such as 'is often forgetful in daily activities', judgements that may be applied differently by researchers in different centres, could result in thresholds of diagnosis that differ considerably.

Questions of diagnostic validity inevitably are greater for disorders in which no validated biological marker exists. This is true not only of ADHD or other childhood disorders, but of health care in general. Many conditions have signs or symptoms (e.g. height, blood pressure, hyperactive-impulsive behaviour) represented by measures on a continuum. These signs and symptoms, be they physical, emotional or psychopathological, require us to consider dimensional and categorical approaches to classification together with issues linked to development from childhood to adulthood. Taylor \& Rutter (2002) have explored these issues in depth.

Given the heterogeneity of clinical signs, symptoms, comorbidities and presentations, as well as the progression of evolving diagnostic systems, ADHD is possibly better conceptualised as a heterogeneous, complex neurodevelopmental constellation of problems rather than a single disorder (Zwi et al, 2000). 


\section{Does ADHD exist?}

Not surprisingly, critics have challenged fundamental issues relating to ADHD, including the validity of the 'disorder' construct itself. Timimi (2001a) argues that the cut-off between normal behaviour and ADHD is arbitrary, and questions who defines it and why. He also asks whether ADHD is a research-generated concept with little relation to the complexity found in clinical practice. He subsequently criticises authors who suggest that the use of psychostimulants is 'nothing less than a call to doctors to medicate children for social control purposes' (Timimi, 2001b).

Concern about 'periodic inaccurate portrayal' of ADHD in the media led a consortium of 74 internationally acclaimed ADHD researchers to publish a consensus statement in which they argue in favour of the validity of the diagnosis (Barkley et al, 2002b). The intention of the statement was to demonstrate consensus among a large body of established clinical researchers regarding the current state of the evidence about ADHD as a genuine disorder (Barkley, 2002b) and the signatories cite support from the US Surgeon General, the American Medical Association, the American Academy of Child and Adolescent Psychiatry, the American Psychological Association and the American Academy of Pediatrics.

The statement describes ADHD as a syndrome characterised by deficiencies in a set of psychological abilities that pose serious harm to most of those who have it. At the core of the disorder are deficits in behavioural inhibition and sustained attention, leading to impaired social, educational and occupational functioning as well as difficulties with social rules, norms and laws, and increased risk of physical injury and accidental poisoning (Barkley et al, 2002).

The document, however, is a statement of opinion rather than a scientific argument, and it quickly generated criticism (Jureidini, 2002). Regrettably, it falls short of the requirements of evidence-based practice, which strives to evaluate the strengths and weaknesses of any question through the use of transparent methodologies that reduce known and unknown bias. It argues that, as 'a matter of science, the notion that ADHD does not exist is simply wrong'. This may be correct, and the statement's thesis may be supported by the authors' original work. However, by presenting a narrative statement rather than a scientific argument with a transparent methodology, critical appraisal of the literature and detailed referencing of each point made, the scientific validity of this document is weakened and it belongs not to the domain of scientific argument but to that of expert opinion. This is essentially a presentational point - there is considerable evidence supporting the existence of ADHD, even if it is not cited.

\section{Prevalence and aetiology}

DSM-IV gives prevalence estimates for ADHD of $3-5 \%$ in school-aged children, but studies in different centres and countries using earlier versions of the DSM give rates that vary from $1.7 \%$ to $16.1 \%$ (Jadad et al, 1999).

Comorbid psychiatric disorders are common in children with ADHD. These include oppositional defiant disorder $(35 \%)$, conduct disorder $(28 \%)$, anxiety disorder $(26 \%)$, depressive disorder $(18 \%)$ and learning difficulties (12\%) (Green et al, 1999).

The aetiology of ADHD is unclear (Green, 1999). There is evidence that it has a genetic component, and environmental factors may also be implicated. Studies have shown that ADHD in childhood is highly heritable (0.8) (Taylor et al, 1998), but inheritance is complex and likely to be the result of several genes acting together.

New genetic research techniques are being used that may well improve our understanding. Traditional molecular genetic techniques have been supplemented by quantitative trait loci (QTL) mapping, an approach that is useful when traits (such as hyperactivity) are continuously distributed in the population (Plomin, 1999).

Molecular genetic studies have shown associations between ADHD and dopamine receptor genes and the dopamine transporter $\mathrm{DAT}_{1}$ (Asherson \& Curran, 2001; Barr, 2001). An international study is currently under way in the IMAGE project (Asherson et al, 2003). Hypotheses have also been presented about the roles of other neurotransmitters, including noradrenaline (Arnsten, 2000; Biederman \& Spencer, 2000) and serotonin (Quist \& Kennedy, 2001). Some evidence exists regarding cognitive deficits in ADHD that affect executive functioning and inhibitory control (Taylor et al, 1998) and lead to altered perception of time and an extreme dislike of waiting (Sonuga-Barke et al, 1994).

It is not clear how environmental and genetic factors interact in the aetiology of ADHD in childhood. The disorder may result in behaviour that is particularly challenging for parents and consequent aggressive parenting might contribute to a worsening of hyperactivity (Woodward et al, 1998).

\section{Treatment}

Concern has been raised about possible overprescription of stimulants to children (Zito et al, 2000 ) and initially this may have deterred professionals, particularly in the UK and the rest of 
Europe, from developing specialist services for children diagnosed with ADHD and similar disorders (Taylor et al, 1998). In 1999, it was estimated that the use of stimulants was 30 times higher in the USA than in the UK (Taylor, 1999), but we believe that increasing information about ADHD is resulting in a rise in their prescription in the UK (Zwi et al, 2000).

Systematic reviews of the use of stimulants in ADHD concluded that, on balance, there is evidence of their benefit, at least in the short term (Miller et al, 1998; Jadad et al, 1999; Lord \& Paisley, 2000). However, Lord \& Paisley thought the overall methodological quality of trials in the ADHD literature to be poor, with a consequent high probability of bias. In their meta-analysis of 62 methylphenidate trials, Schachter et al (2001) were even more cautious, reporting a modest benefit from methylphenidate that was balanced against adverse effects and publication bias that might have skewed results.

\section{The MTA}

The Multimodal Treatment Study of Children with Attention-Deficit/Hyperactivity Disorder (MTA) was the largest, most rigorous randomised controlled trial to date, involving 579 children aged 79.9 years (MTA Cooperative Group, 1999). Despite methodological issues raised by some authors (Boyle \& Jadad, 1999; Taylor, 1999), it is a trial that confirmed the effectiveness of medication management in children and adolescents.

The MTA also found, controversially, that intensive behavioural therapy involving the child, family and teachers added little to well-supervised medication management. Klassen et al (1999) have suggested that this might be an artefact related to trial methodology. Behavioural interventions, for example, may be better at reducing 'associated features' of ADHD such as conflictual relationships or academic achievement, outcomes that may be difficult to measure. In contrast, stimulants may be most effective at reducing the core symptoms of ADHD (inattention, hyperactivity and impulsivity) and both the intervention and the outcome lend themselves well to highly controlled experimental studies.

\section{The landmark cohort studies}

Three cohort studies of children with diagnoses of ADHD (or earlier diagnostic terms used to describe what we now call ADHD) have followed individuals from childhood into adulthood (Weiss et al, 1985; Mannuzza et al, 1993; Rasmussen \& Gillberg, 2000). They all report relatively low rates of ADHD in the adult years compared with childhood and adolescence, but they also report that those who had had childhood ADHD (compared with controls) showed higher rates in adulthood of impaired educational and occupational outcomes, antisocial personality disorder, substance misuse and persistent social impairment.

It is difficult to compare these three cohort studies directly with one another because their selection criteria, drop-out rates and reported outcomes differ. This is further complicated by heterogeneity regarding clinical signs, symptoms, comorbidity and presentations, not to mention changes in diagnostic classification systems over time. However, we give a brief outline of each study below.

\section{Weiss et al's Montreal study}

The Montreal study (Weiss et al, 1985) followed 63 hyperactive children and 41 controls for 15 years, until they were in their mid-20s. Diagnostic interviews were not blinded and the loss to follow-up over 15 years was 33.6\%. DSM-III was not in use at the start of the study, so the authors attributed retrospective DSM-III diagnoses at publication. All of the children received diagnoses of ' $\mathrm{ADD}(\mathrm{H})^{\prime}$ (attention-deficit disorder (hyperactivity), and 'the majority' had an associated conduct disorder.

They reported on symptoms of 'the hyperactive syndrome' and found that $66 \%$ of hyperactive individuals (compared with $7 \%$ of the control group) complained of at least one disabling symptom. They did not report the rates of those with the full DSMIII diagnosis at the end of the 15-year period, which is surprising. Interestingly, the only DSM-III diagnosis that differed between the two groups was antisocial personality disorder, present in $23 \%$ of the hyperactive individuals and $2.4 \%$ of the controls.

Of the hyperactive individuals, $90 \%$ had received 10-20 therapeutic interviews and 10\% had received family therapy during childhood and adolescence. None had been prescribed methylphenidate but four had taken dexamphetamine for 6 months or 'on and off' for 2 years; 20 had been treated with chlorpromazine for between 6 months and 2 years.

\section{Mannuzza et al's New York study}

Mannuzza et al's (1993) study in New York followed two cohorts of a total of 207 predominantly middleclass White boys of average IQ referred to a child psychiatric clinic, from childhood to their mid-20s. Conduct disorder was virtually absent from this group because those with aggression or antisocial behaviour were excluded. Assessors were blind to the person's diagnostic status. Loss to follow-up was $12 \%$ for the first cohort and $18 \%$ for the second 
over a period of $15-21$ years. About $85-90 \%$ of those with hyperactivity had been prescribed stimulant drugs in childhood. Some of these received stimulants only during childhood, whereas others continued to receive them for years (S. Mannuzza, personal communication, 2003).

In late adolescence, ADHD was present in $40 \%$ of the index cases and 3\% of controls (Gittelman et al, 1985 ), and $27 \%$ of the index group, $v .8 \%$ of the controls, had antisocial personality disorder. By the time the subjects had reached a mean age of 25, 'clinically impairing ADHD symptoms and syndromes' were present in $11 \%$ of the index group and in only $1 \%$ of the controls; in their second cohort only $4 \%$ of the index group and none of the controls had ADHD (Mannuzza et al, 1993, 1998).

Rasmussen \& Gillberg's Swedish study

Rasmussen \& Gillberg's (2000) study in Sweden followed a community sample of 61 children with ADHD and comorbid developmental coordination disorder and 46 controls from childhood to adulthood. Diagnosis in childhood, as in the Montreal and New York studies, used a diagnostic system different from DSM-IV, so the authors scrutinised records and rediagnosed them according to DSMIV. However, the index cases included children with motor and perceptual problems and the rediagnosed sample included 39 with ADHD and developmental coordination disorder, 11 with ADHD only and 5 with developmental coordination disorder only.

A unique aspect of this study is that none of the index cases had ever received stimulants. Followup extended over 15 years and loss to follow-up in both groups was $10 \%$. Assessments of psychiatric status in adulthood were blinded.

In terms of 'current ADHD' they found that $49 \%$ of the index cases and 9\% of the controls had 'marked symptoms of ADHD at age 22'. They also found that almost $60 \%$ of the children in the index group, compared with $13 \%$ in the control group, had 'a poor outcome', which included drug or alcohol misuse, living off a disability pension or welfare benefits, major personality disorder, chronic severe psychiatric disorder, autistic-spectrum disorder, and conviction for a criminal offence.

\section{Extending the concept of ADHD to adulthood}

It is not a simple matter to extend the concept of ADHD to adulthood. Should we think of it as a developmental disorder, showing continuity into adulthood (like, for example, autistic-spectrum disorders and conduct disorder, which in adulthood is observed as antisocial behaviour and personality disorder), or as a psychiatric disorder (like depression)?

The diagnostic validity of ADHD poses more of a challenge in adults than it does in children, given the need for retrospective information, the extent of comorbidity with other disorders (Shaffer, 1994) and the fact that DSM-IV criteria have been validated only in children and adolescents, not in adults (Weiss et al, 2002).

Wender, who described adult attention-deficit disorder as long ago as 1981, suggests that his Utah group has 'consistently found' that many adults with persistent ADHD symptoms do not report them (Wender, 2001).

Diagnostic interview tools that identify childhood symptoms may increase diagnostic validity in adult populations in which there is a high probability of childhood ADHD, as in groups referred to specialist ADHD clinics, but in the general population the picture may be different.

Mannuzza et al (2002) report on long-term recall of childhood ADHD by adults who had been diagnosed in childhood and followed up. Interviewers blind to the childhood diagnosis used a semi-structured interview to ascertain whether adults reporting symptoms from childhood were able to provide sufficient information to confirm a retrospective ADHD diagnosis. In this clinic-referred population, the interviews achieved high sensitivity (0.78) and specificity (0.89) (Box 1) for adult recall of childhood ADHD symptoms. Thus, in a population in which the prevalence of true-positive cases should be much higher than in the general population anyway, the instrument used by Mannuzza et al appears to be helpful. However,

\section{Box 1 Sensitivity $v$.specificity}

A diagnostic instrument with high sensitivity accurately identifies those with the disorder, who obtain a positive result using the instrument (the 'true positives').

The specificity is the proportion of people without the disorder that the instrument correctly identifies as not having it (i.e. who obtain a negative result). An instrument with low specificity gives a high number of 'false positives': people who do not have the disorder but whom the instrument identifies as having it.

These measures of an instrument's utility are interrelated and are also influenced by the disorder's prevalence, i.e. the total number of true-positive cases in the population. 
when they recalculated the figures assuming a 5\% prevalence of ADHD in the general population, the false-positive rate rose substantially, to $75 \%$.

This highlights the danger of making retrospective diagnoses of childhood ADHD on the basis of selfreports in primary care settings and epidemiological surveys, where the prevalence of ADHD in the population is low.

It has also been argued that DSM-IV criteria are inappropriately worded for adults, again because they have been validated in children and adolescents (Murphy et al, 2002). Another issue is the natural history of ADHD. Symptoms and impairment may change as the individual develops, with the hyperactive-impulsive symptoms emerging initially in childhood (Loeber et al, 1992) before declining with age. Symptoms of inattention may emerge later (Applegate et al, 1997) and predominate with age, whereas hyperactivity may become less overt, appearing as restlessness and fidgetiness (Mannuzza et al, 1997; Biederman et al, 2000; Murphy et al, 2002; Weiss et al, 2002).

Some argue, therefore, that DSM-IV diagnostic criteria are too stringent when applied to adults, and point to the finding that in longitudinal studies as many as $66 \%$ continue to report the presence of at least one ADHD symptom severe enough to cause impairment (Murphy et al, 1996; Weiss et al, 2002). For example, the DSM-IV diagnostic criteria include the presence of symptoms before the age of 7 years, reflecting the developmental nature of the disorder. This early onset may be difficult to ascertain retrospectively in the absence of a clearly documented history of childhood ADHD, and Murphy et al (2002) argue that it is unjustifiable to maintain this threshold, especially since DSM-IV field trials have shown that it significantly diminishes the reliability of the diagnosis (Applegate et al, 1997).

If the diagnostic criteria are too restrictive when applied to adults, it may lead to underdiagnosis (Millstein et al, 1997; Weiss et al, 2002; Murphy \& Barkley, 2002). This could, of course, be argued the other way too and, in the absence of further validation studies, simply modifying the diagnostic criteria might lead to higher rates of false-positive diagnosis.

Another issue of importance is the difference between adults diagnosed with ADHD in childhood and adults who present with suspected ADHD with no confirmed childhood ADHD diagnosis. Children with ADHD are usually taken to clinics by parents, whereas adults who attend clinics are usually selfreferred. Thus, factors associated with self-referral, such as educational and socio-economic status, may influence the composition of this population (Murphy \& Barkley, 1996).
Patterns of comorbidity appear to be different in these two groups. Murphy \& Barkley (1996) report that clinic-referred adults were more likely to have comorbid anxiety disorders (50\% where affected), whereas hyperactive children followed to adulthood were more commonly found to have conduct, substance misuse and antisocial personality disorders.

Faraone (2000) suggests that we should view the diagnosis of ADHD as we do the construct of IQ, using 'different test batteries for different age groups and within a single battery [considering] a score high or low in reference to people of the same age'. He acknowledges, however, that age may be an imperfect proxy for development and suggests that the individual's developmental stage at the time of the diagnosis might be used instead.

He also highlights that changes in diagnostic criteria from DSM-III onwards have introduced a hierarchical approach to diagnosis rather than a 'comorbidity paradigm', thereby excluding some diagnoses in the presence of others. For example, where ADHD and depression are both present, the primary diagnosis would be that of ADHD. Depending on how these rules were applied, comorbidity and prevalence information might be lost. He asserts that a clash of theoretical paradigms is an important aspect of the debate over validity of adult ADHD. Researchers using hierarchical diagnoses would find fewer cases than those using a comorbidity paradigm, and clinicians using developmentally sensitive diagnoses would 'find adult ADHD where others do not'.

\section{Treatment of adult ADHD}

Although it might be argued that the weight of the available literature' shows that adult ADHD can be diagnosed reliably through historical self-reports of childhood symptoms (Spencer et al, 1995), it has also been shown that, to avoid false-positive diagnoses, it is vital to obtain contemporaneous data to substantiate retrospective diagnoses (Mannuzza et al, 2002).

As mentioned above, high interrater reliability between expert assessors may increase the internal validity of trials. Until questions regarding the validity of adult ADHD are settled through further validation studies, however, the external validity of these trials remains uncertain and the generalisation of results to others with 'adult ADHD' should be made with caution.

We will therefore limit our comments regarding treatment interventions to saying that (at the time of writing) there is limited evidence from a number of small trials (the largest involved only 41 
participants) to suggest that methylphenidate (Spencer et al, 1995; Dorrego et al, 2002), mixed amphetamine salts (Spencer et al, 2001), bupropion (Wilens et al, 2001), desipramine (Wilens et al, 1996), lithium (Dorrego et al, 2002), modafinil (Taylor \& Russo, 2000) and pemoline (Wilens et al, 1999) may be beneficial in adult ADHD. The selective inhibitor of the noradrenaline transporter, atomoxetine, showed promise in two larger trials (Michelson et al, 2003).

\section{Future research}

Much still needs to be understood about ADHD, particularly in adulthood. Its core symptoms of inattention, hyperactivity and impulsivity, as well as other ADHD-related behaviours, personality traits and disabilities, need thorough developmental observation and study across the life span. Further investigation is also needed on the role and interaction of genetic and environmental factors in the aetiology and course of ADHD throughout life.

High-quality diagnostic validity studies are still necessary and large, high-quality randomised controlled trials are needed in adult ADHD. It is also vital that transparent methodologies are used and reported in research publications and that journal editorial boards adopt protocols such as the revised CONSORT statement on the reporting of randomised controlled trials (Moher et al, 2001).

Along with primary research, secondary research in the form of transparent systematic reviews and meta-analyses of the literature are vital to answer many contentious questions that arise in this field.

\section{Conclusions}

It is likely that professionals in adult mental health will increasingly receive referrals about adults who wish to be assessed and treated for ADHD. Some of these will be the young people who have been diagnosed and treated for ADHD in childhood and adolescence. Others may be parents of those with ADHD or people who wonder whether their problems might arise from 'undiagnosed ADHD'.

The imaginative work that went into the landmark cohort studies has been invaluable, despite their limitations. We now know that many children with hyperactivity go on to have long-term problems and poorer outcomes than those without it.

What is uncertain, however, is whether the same group of children entering cohort studies 25 years ago with diagnoses such as hyperactivity, minimal brain dysfunction or motor perception dysfunction would have been entered into these studies if current criteria were applied to their selection. Although this may be likely, we cannot be sure that we are talking about the same condition when diagnostic criteria have changed. We cannot assume with certainty that the cohorts assembled then are the same as those we now identify as having ADHD. This is further complicated by the heterogeneity within ADHD in terms of the range of presentations and comorbid problems.

With so many more children being diagnosed and treated today, what we do not know is whether early intervention and treatment over a longer period will prevent the poor outcome seen in the landmark studies. The need for further, well-designed cohort studies is as important today as it was 30 years ago.

Finally, we would like to echo the words of Faraone regarding adult $A D H D$, that 'research should focus not only on the validity of the disorder, but also on the validity of the theories that buttress the diagnosis' (Faraone, 2000). There may be stronger grounds for the diagnostic validity of ADHD in children and adolescents, albeit with some reservations, than in adults. There should, however, still be considerable debate and research regarding the diagnostic validity of both.

\section{References}

American Psychiatric Association (1968) Diagnostic and Statistical Manual of Mental Disorders (2nd edn) (DSM-II). Washington, DC: APA.

American Psychiatric Association (1980) Diagnostic and Statistical Manual of Mental Disorders (3rd edn) (DSM-III). Washington, DC: APA.

American Psychiatric Association (1987) Diagnostic and Statistical Manual of Mental Disorders (3rd edn, revised) (DSM-III-R). Washington, DC: APA.

American Psychiatric Association (1994) Diagnostic and Statistical Manual of Mental Disorders (4th edn) (DSM-IV). Washington, DC: APA.

Applegate, B., Lahey, B. B., Hart, E. L., et al (1997) Validity of the age-of-onset criterion for ADHD. A report from the DSM-IV field trials. Journal of the American Academy of Child and Adolescent Psychiatry, 36, 1211-1221.

Arnsten, A. F. (2000) Genetics of childhood disorders: XVIII. ADHD, Part 2: Norepinephrine has a critical modulatory influence on prefrontal cortical function. Journal of the American Academy of Child and Adolescent Psychiatry, 39, 1201-1203.

Asherson, P. J. \& Curran, S. (2001) Approaches to gene mapping in complex disorders and their application in child psychiatry and psychology. British Journal of Psychiatry, 179, 122-128.

Asherson, P., Taylor, E., Craid, I., et al (2003) IMAGE Mapping Susceptibility Genes for Attention Deficity Hyperactivity Disorder. http://www.iop.kcl.ac.uk/IoP/ Departments/SGDPsy/research/IMAGE.shtml

Barkley, R. A. (1990) Attention-Deficit Hyperactivity Disorder: A Handbook for Diagnosis and Treatment. New York: Guilford Press.

Barkley, R. A. (2002a) Does the International Consensus Statement on ADHD leave room for healthy scepticism? (reply). European Child and Adolescent Psychiatry, 11, 241242.

Barkley, R. A. (2002b) International consensus statement on ADHD. Journal of the American Academy of Child and Adolescent Psychiatry, 41, 1389. 
Barr, C. L. (2001) Genetics of childhood disorders: XXII. ADHD, Part 6: The dopamine $\mathrm{D}_{4}$ receptor gene. Journal of the American Academy of Child and Adolescent Psychiatry, 40, 118-121.

Biederman, J. \& Spencer, T. J. (2000) Genetics of childhood disorders: XIX. ADHD, Part 3: Is ADHD a noradrenergic disorder? Journal of the American Academy of Child and Adolescent Psychiatry, 39, 1330-1333.

Biederman, J., Mick, E. \& Faraone, S. (2000) Age-dependent decline of symptoms of attention deficit hyperactivity disorder. Impact of remission definition and symptom type. American Journal of Psychiatry, 157, 816-818.

Boyle, M. H. \& Jadad, A. R. (1999) Lessons from large trials: the MTA study as a model for evaluating the treatment of childhood psychiatric disorder. Canadian Journal of Psychiatry, 44, 991-998.

Bradley, C. (1937) The behavior of children receiving benzedrine. American Journal of Psychiatry, 94, 577-585.

Clarke M. \& Oxman, A. D. (2003) Cochrane Reviewers' Handbook 4.1.6 [updated January 2003]. Cochrane Library, issue 1. Oxford: Update Software.

Dorrego, M. F., Canevaro, L., Kuzis, G., et al (2002) A randomized, double-blind, crossover study of methylphenidate and lithium in adults with attention-deficit/ hyperactivity disorder. Preliminary findings. Journal of Neuropsychiatry and Clinical Neurosciences, 14, 289-295.

Faraone, S. V. (2000) Attention-deficit hyperactivity disorder in adults: implications for theories of diagnosis. Current Directions in Psychological Science, 9, 33-36.

Frick, P. J., Lahey, B. B., Applegate, B., et al (1994) DSM-IV field trials for the disruptive behavior disorders. Symptom utility estimates. Journal of the American Academy of Child and Adolescent Psychiatry, 33, 529-539.

Gittelman, R., Mannuzza, S., Shenker, R., et al (1985) Hyperactive boys almost grown up: I. Psychiatric status. Archives of General Psychiatry, 42, 937-947.

Green, M., Wong, M., \& Atkins, D., et al (1999) Diagnosis and Treatment of Attention-Deficit/Hyperactivity Disorder in Children and Adolescents. Technical Review Number 3. Agency for Health Care Policy and Research, AHCPR publication no. 99-0050. Rockville, MD: American Medical Association

Jadad A. R., Boyle, M., Cunningham, C., et al (1999) Treatment of Attention-Deficit/Hyperactivity Disorder. Evidence Report/ Technology Assessment Number 11. Agency for Health Care Policy and Research and Quality. Rockville, MD: American Medical Association.

Jureidini, J. (2002) Does the International Consensus Statement on ADHD leave room for healthy scepticism? European Child and Adolescent Psychiatry, 11, 240.

Klassen, A., Miller, A., Raina, P., et al (1999) Attention-deficit hyperactivity disorder in children and youth: a quantitative systematic review of the efficacy of different management strategies. Canadian Journal of Psychiatry, 44, 1007-1016.

Lahey, B. B. (1994) DSM-IV field trials for attention-deficit hyperactivity disorder in children and adolescents. American Journal of Psychiatry, 151, 1673-1685.

Loeber, R., Green, S. M., Lahey, B. B., et al (1992) Developmental sequences in the age of onset of disruptive child behaviors. Journal of Child and Family Studies, $\mathbf{1}$ 21-41.

Lord, J. \& Paisley, S. (2000) The Clinical Effectiveness and Cost-effectiveness of Methylphenidate for Hyperactivity in Childhood (Version 2). London: National Institute for Clinical Excellence.

Mannuzza, S., Klein, R. G., Bessler, A., et al (1993) Adult outcome of hyperactive boys. Educational achievement, occupational rank, and psychiatric status. Archives of General Psychiatry, 50, 565-576.

Mannuzza, S., Klein, R. G., Bessler, A., et al (1997) Educational and occupational outcome of hyperactive boys grown up. Journal of the American Academy of Child and Adolescent Psychiatry, 36, 1222-1227.

Mannuzza, S., Klein, R. G., Bessler, A., et al (1998) Adult psychiatric status of hyperactive boys grown up. American Journal of Psychiatry, 155, 493-498.
Mannuzza, S., Klein, R. G., Klein, D. F., et al (2002) Accuracy of adult recall of childhood attention-deficit hyperactivity disorder. American Journal of Psychiatry, 159, 1882-1888.

Michelson, D., Adler, L., Spencer, T., et al (2003) Atomoxetine in adults with ADHD: two randomized, placebocontrolled studies. Biological Psychiatry, 53, 112-120.

Miller, A., Lee, S., Raina, P., et al (1998) A Review of Therapies for Attention-Deficit/Hyperactivity Disorder. Ottawa Canadian Coordination Office for Health Technology Assessment.

Millstein, R. B., Wilens, T. E., Biederman, J., et al (1997) Presenting ADHD symptoms and subtypes in clinically referred adults with ADHD. Journal of Attention Disorders, 2, 159-166.

Moher, D., Schulz, K. F. \& Altman, D. G. (2001) The CONSORT statement: revised recommendations for improving the quality of reports of parallel-group randomised trials. Lancet, 357, 1191-1194.

MTA Cooperative Group (1999) A 14-month randomized clinical trial of treatment strategies for attention-deficit/ hyperactivity disorder. Multimodal Treatment Study of Children with ADHD. Archives of General Psychiatry, 56, 1073-1086.

Murphy, K. \& Barkley, R. A. (1996) Attention deficit hyperactivity disorder adults. Comorbidities and adaptive impairments. Comprehensive Psychiatry, 37, 393-401.

Murphy, K. R., Barkley, R. A. \& Bush, T. (2002) Young adults with attention deficit hyperactivity disorder: subtype differences in comorbidity, educational, and clinical history. Journal of Nervous and Mental Disease, 190, 147-157.

Plomin, R. (1999) Genetics of childhood disorders: III Genetics and intelligence. Journal of the American Academy of Child and Adolescent Psychiatry, 38, 786-788.

Quist, J. F. \& Kennedy, J. L. (2001) Genetics of childhood disorders: XXIII. ADHD, Part 7: The serotonin system. Journal of the American Academy of Child and Adolescent Psychiatry, 40, 253-256.

Rasmussen, P. \& Gillberg, C. (2000) Natural outcome of ADHD with developmental coordination disorder at age 22 years. A controlled, longitudinal, community-based study. Journal of the American Academy of Child and Adolescent Psychiatry, 39, 1424-1431.

Schachter, H. M., Pham, B., King, J., et al (2001) How efficacious and safe is short-acting methylphenidate for the treatment of attention-deficit disorder in children and adolescents? A meta-analysis. Canadian Medical Association Journal, 165, 1475-1488.

Shaffer, D. (1994) Attention-deficit hyperactivity disorder in adults. American Journal of Psychiatry, 151, 633-638.

Sonuga-Barke, E. J. S., Houlberg, K., Hall, M., et al (1994) When is "impulsiveness" not impulsive? The case of hyperactive children's cognitive style. Journal of Child Psychology and Psychiatry and Allied Disciplines, 35, 1247-1253.

Spencer, T., Wilens, T., Biederman, J., et al (1995) A doubleblind, crossover comparison of methylphenidate and placebo in adults with childhood-onset attention-deficit hyperactivity disorder. Archives of General Psychiatry, 52, 434-443.

Spencer, T., Biederman, J., Wilens, T., et al (2001) Efficacy of a mixed amphetamine salts compound in adults with attention-deficit/hyperactivity disorder. Archives of General Psychiatry, 58, 775-782.

Still, G. F. (1902) Some abnormal physical conditions in children: the Goulstonian Lectures. Lancet, 1, 1008-1012, 1077-1082.

Taylor, E. (1999) Development of clinical services for attention deficit/hyperactivity disorder. Archives of General Psychiatry, 56, 1097-1099.

Taylor, F. B. \& Russo, J. (2000) Efficacy of modafinil compared to dextroamphetamine for the treatment of attention deficit hyperactivity disorder in adults. Journal of Child and Adolescent Psychopharmacology, 10, 311-320.

Taylor, E. \& Rutter, M. (2002) Classification: conceptual issues and substantive findings. In Child and Adolescent Psychiatry (4th edn) (eds E. Taylor \& M. Rutter), pp. 3-17. Oxford: Blackwell Science. 
Taylor, E., Sergeant, J., Doepfner, M., et al (1998) Clinical guidelines for hyperkinetic disorder. European Child and Adolescent Psychiatry, 7, 184-200.

Timimi, S. (2001a) Evidence and belief in attention-deficit hyperactivity disorder. $B M J, 322,555$.

Timimi, S. (2001b) Example of medical imperialism not evidence based practice. BMJ website: internet instan response. http://bmj.bmjjournals.com/cgi/eletters/ 323/7323/1232\#17891

Toone, B. K. \& van der Linden, G. J. (1997) Attention deficit hyperactivity disorder or hyperkinetic disorder in adults. British Journal of Psychiatry, 170, 489-491.

Weiss, G., Hechtman, L., Milroy, T., et al (1985) Psychiatric status of hyperactives as adults. A controlled prospective 15-year follow-up of 63 hyperactive children. Journal of the American Academy of Child Psychiatry, 24, 211-220.

Weiss, M., Murray, C. \& Weiss, G. (2002) Adults with attention-deficit/hyperactivity disorder. Current concepts. Journal of Psychiatric Practice, 8, 99-111.

Wender, P. H. (2001) Adults with ADHD: An overview. In Adult Attention Deficit Disorder: Brain mechanisms and Life Outcomes (eds J. E. Wasserstein, L. E. E. Wolf \& F. F. LeFevre), pp. 1-16. New York: New York Academy of Sciences.

Wilens, T. E., Biederman, J., Prince, J., et al (1996) Six-week, double-blind, placebo-controlled study of desipramine for adult attention deficit hyperactivity disorder. American Journal of Psychiatry, 153, 1147-1153.

Wilens, T. E., Biederman, J., Spencer, T. J., et al (1999) Controlled trial of high doses of pemoline for adults with attention-deficit/hyperactivity disorder. Journal of Clinical Psychopharmacology, 19, 257-264.

Wilens, T. E., Spencer, T. J., Biederman, J., et al (2001) A controlled clinical trial of bupropion for attention-deficit hyperactivity disorder in adults. American Journal of Psychiatry, 158, 282-288.

Woodward, L., Taylor, E. \& Dowdney, L. (1998) The parenting and family functioning of children with hyperactivity. Journal of Child Psychology and Psychiatry and Allied Disciplines, 39, 161-169.

World Health Organization (1992) The International Statistical Classification of Diseases and Related Health Problems, Tenth Revision (ICD-10). Geneva: WHO.

Young, S. \& Toone, B. (2000) Attention deficit hyperactivity disorder in adults: clinical issues. A report from the first NHS clinic in the UK. Counselling Psychology Quarterly, 13 313-319.

Zito, J., Safer, D. J., dosReis, S., et al (2000) Trends in the prescribing of psychotropic medications to preschoolers. $J A M A, 283,1025-1030$.

Zwi, M., Ramchandani, P. \& Joughin, C. (2000) Evidence and belief in ADHD. BMJ, 321, 975-976.

\section{Multiple choice questions}

1 Questions about the validity of adult ADHD are still relevant because:

a field trials in 18- to 35-year-olds that demonstrate the validity of DSM-IV diagnostic criteria for ADHD require replication

b results of existing small RCTs in adult ADHD cannot be generalised to other clinical populations, owing to a heterogeneity of clinical signs, symptoms, comorbidity and presentation, and issues of diagnostic validity

c field trials validating some DSM-IV diagnostic criteria for ADHD involved only children and adolescents

d retrospective evaluation of childhood symptoms poses significant methodological challenges to the diagnostic validity of adult ADHD.

2 Cohort trials of children with hyperactivity:

a have demonstrated that, in general, hyperactive children show better outcomes than controls in adulthood, which is explained by their entrepreneurial success

b are said to show lower than expected rates of ADHD in adulthood by those who believe DSM-IV criteria to be insufficiently sensitive to the condition

c are not easily compared because selection criteria, numbers lost to follow up and reported outcomes differ between studies

d have shown poorer outcomes in children with hyperactivity than in controls.

3 The use of stimulants in children and adolescents with ADHD:

a has been shown to reduce hyperactivity-impulsivity and inattention in the short term

$b$ has been the subject of a number of high-quality systematic reviews

c has shown a downward trend in prescriptions in recent times

d has been shown to prevent negative outcomes in adulthood.

4 Randomised controlled trials in ADHD patients:

a have not been done using stimulants in children, because of ethical considerations

$\mathrm{b}$ is not the appropriate study methodology for testing medication interventions

c are no longer necessary since the $\mathrm{D}_{4}$ gene has been shown to be pathognomonic of the disorder

$\mathrm{d}$ have been evaluated in major systematic reviews by Miller et al, Jadad et al and Lord \& Paisley.

5 Psychiatric comorbidity in ADHD:

a is high in children, with about $60 \%$ showing comorbid disorders

$\mathrm{b}$ is the exception rather than the rule because it occurs infrequently

c may be affected by assessors' use of hierarchical diagnostic systems

d appears far less frequently than expected (at about $5 \%)$ in children with this complex neurodevelopmental disorder.

\section{MCQ answers}

\begin{tabular}{|c|c|c|c|}
\hline 1 & 2 & 3 & 4 \\
\hline $\mathrm{F}$ & a $F$ & a $\mathrm{T}$ & a F \\
\hline $\mathrm{T}$ & b $\mathrm{T}$ & b $\mathrm{T}$ & b F \\
\hline $\mathrm{T}$ & c $\mathrm{T}$ & C $\mathrm{F}$ & C F \\
\hline $\mathrm{T}$ & $\mathrm{d} T$ & d F & $\mathrm{d} \mathrm{T}$ \\
\hline
\end{tabular}

